\title{
TAPERING OPIOID PRESCRIPTIONS AND REDUCING POLYPHARMACY FOR INPATIENTS WITH SPINAL CORD INJURY AT RANCHO LOS AMIGOS NATIONAL REHABILITATION CENTER
}

\author{
Alan Marc Atkins; Fernando Gonzalez, PhD; Brian Joyo, PharmD; Mindy Lipson Aisen, MD
}

\section{INTRODUCTION}

Reducing opioid prescriptions in the United States is vital. The Department of Health and Human Services has declared that the current rate of deaths from overdose of prescription opioids is an epidemic [1]. U.S. deaths from overdose of prescribed opioids increased by a factor of four from 1999 to 2010 , with 16,651 prescription opioid deaths recorded in 2010. This number exceeded heroin deaths by more than a factor of five. In addition to the high mortality, overuse of opioid analgesics causes withdrawal, impaired cognitive function, depression, loss of motivation, constipation, and endocrine and sexual dysfunction. What is more, patients on high levels of opioids also experience hyperalgesia (decreasing pain threshold), which can mask the resolution of the pre-existing pain condition [2].

How did this epidemic of opioid overuse happen? A newly coined acronym is telling: OOPS, for opioid overuse pain syndrome [3]. The 1999 edition of the Merck Manual emphasized that opioids were often underused for chronic nonterminal pain due to over-concern about addiction. At that time, the Joint Commission on Accreditation of Health Care Organizations declared pain assessment to be a "fifth vital sign," and the prescribing culture changed dramatically. However, although opioids are appropriate for postoperative pain, tooth abscess, and cancer, they do not have proven efficacy or safety for treating long-term pain in persons with spinal cord injury (SCl) [4-5]. Many trauma patients are prescribed narcotic analgesics and sedatives in acute care. Unfortunately, it is possible that postoperative and rehabilitation primary care clinicians did not pause to identify the source of pain; they simply renewed medications. Why? Was it time constraints, patient pressures, lack of training? How can we improve prescribing decisions in rehabilitation hospitals and clinics?

\section{THE PROBLEM AT RANCHO LOS AMIGOS}

Rancho Los Amigos National Rehabilitation Center (RLANRC) is a public hospital in Los Angeles County with 395 licensed beds for rehabilitation of $\mathrm{SCl}$, traumatic brain injury, stroke, general neurological conditions, gerontology, and reconstruction. We admit an average of 3,600 newly injured individuals each year, including 250 with SCl (54\% traumatic, $40 \%$ tetraplegic). Chronic pain is reported after $\mathrm{SCl}$ in about 75 percent of patients; tends to persist; and is severe in about one third, being a leading cause of disability among veterans [6]. In 2013, RLANRC served 10,905 unique outpatients, including 1,918 with SCl. Many of these patients present sensitive chronic pain cases, including a history of drug addiction, use of opioids for 10 or more years, and pain so severe that they report their quality of life to be very low when not using opioid analgesics. Many come from poverty, highrisk lifestyles, and dysfunctional families.

Serious complications related to opioid and sedative overprescription began to be documented at RLANRC as a result of a greater emphasis on creating a coordinated continuum of care and patient safety. We also saw drug-seeking and disruptive behaviors (belligerence, yelling, throwing things, and threatening nursing staff). We realized that our SCl patients were overmedicated with muscle relaxants, pain killers, opioids, and sedatives.

We determined that the overuse of medication had arisen through five different avenues: (1) polypharmacy in general (which is common in recently hospitalized patients with comorbidities and disabilities), especially the "unholy trinity" drug combination (opioids, benzodiazepines, and muscle relaxants with sedating properties); (2) sedatives for sleep in a population at risk for sleep apnea; (3) overuse of acetaminophen 
(risk of liver toxicity); (4) opioid use for inappropriate conditions; and (5) inadequate awareness of the need to decrease dosages as people age, or have changes in ability to metabolize medications, or have changes in body mass. Polypharmacy that includes opioids is especially dangerous because it is impossible to predict the side effects of a combination of drugs from the pharmacological profiles of the individual drugs.

\section{PLANNING OUR INTERVENTION}

Overuse of opioids usually becomes entrenched during inpatient stay. Therefore, our primary aim was to eliminate opioid overuse and reduce polypharmacy in our inpatients. How could we do it? We assembled an interdisciplinary ad hoc committee of clinicians: specialist physicians, nurses, physician's assistants, nurse practitioners, occupational therapists, physical therapists, social workers, clinicians from Psychiatry and Psychology, patient advocates, and the Patient Advisory Board. The goals of this ad hoc Pain Committee were to ensure the safety of patients, educate patients and providers to the danger of opioid use, and provide optimal medical and nonmedical pain relief interventions. The team developed this project during about a year prior to implementation. It entailed literature research, direct intervention with physicians, a communications campaign, and training.

\section{Research}

We considered several recent evidence-based guidelines for opioid management [7-8] and success stories such as opioid reduction programs at the Mayo Clinic and Kaiser Permanente [9]. The approach of the Southern California Permanente Medical Group in particular offered a large range of interventions to choose from: education and monitoring of prescribers by the employer, and of patients through imposed "pain contracts"; training of prescribers about the appropriate use of opioids, sedatives, and muscle relaxants; decision support; pharmacy calls to prescribers; pain management specialists; scheduled visits for highdose patients; interdepartmental agreements; and thinking in terms of morphine-equivalent doses. The main lesson from Kaiser was the need for leadership. We chose the route of education and persuasion and devised our own additional interventions, such as extending the role of RLANRC's Patient Safety Officer (PSO), lifestyle counseling by occupational therapists, and psychotherapy from clinical psychologists and social workers.

\section{Case Reviews at Pain Meetings}

One effective way for us to communicate our new expectations to providers and lend them support was to invite various providers from around the hospital to the ad hoc Pain Committee meetings. At the meetings, they could witness the thought and resources being put into the efforts to taper opioid analgesic prescriptions, as well as share difficult cases having to do with opioid prescription.

\section{Communications Campaign}

We developed messaging and scripts for the people on the front lines who were often dealing with patients and their families aggressively demanding pain medications:

We care about your pain, we want to help you cope, but we must first do no harm and your current medications could impair your health. We want to teach you to control your pain using less strong pain medication. Ask your doctor how to successfully manage muscle pain, bone pain, spasms, nervous system pain, depression, and anxiety. Ask your therapist about adaptive exercise, stretching, hot or cold treatments, ultrasound, meditation, music, art, pets, gardening, and Lifestyle Redesign ${ }^{\circledR}$ opportunities. Work with a Peer Mentor.

We developed posters with this kind of messaging, a letter mailed to outpatients, and grassroots-based communication methods with our large population of outpatients. RLANRC has a vibrant outpatient community with strong leadership, active membership, and many community connections. We believe that the patient network communicates faster than our official communications can. This is evidenced by the fact that the most dramatic reduction trends for inpatients 
began before the official lines of communication had been implemented.

\section{Champions}

We developed champions in the different disciplines who would help the less experienced clinicians in person when dealing with a patient who was dissatisfied.

\section{Opioid Equivalents and Tapering Guides}

We provided clinicians with conversion tables to calculate oral-morphine analgesic-equivalent doses for all opioids and encouraged clinicians to think in terms of oral-morphine equivalents. We also provided a guideline for tapering, along with more messaging: "Opioids are not appropriate for chronic pain, only for cancer, postoperative pain, or a tooth abscess." The conversion table and guideline were developed by the Pharmacy Service Chief in collaboration with one of our physicians who had the most experience with tapering and minimizing use of opioids, and these were disseminated by one of our physician assistants. The Pharmacy Service Chief then provided weekly data about usage of these medications.

\section{Patient Safety Officer and Executive Rounds}

RLANRC's PSO (a highly regarded endocrinologist specializing in stress) received weekly information from the pharmacy about patients who were experiencing polypharmacy ( $>10$ drugs) or were receiving a potentially dangerous combination of drugs. With this information, the PSO telephoned providers or directly talked to providers during Executive Rounds For Safety, which included the Chief Medical Officer, nursing leadership, and members of the clinical leadership of the $\mathrm{SCl}$ system of care. The PSO informed the providers about the medication safety issues and asked the provider to adjust the prescription (for example, eliminate some of the unnecessary drugs, decrease the dose of opioids, or eliminate a sleeping pill). The PSO also acted on lists of physicians who might benefit from education about our new policies on opioids, based on their patient prescription levels. The Executive Rounds for Safety were designed to promote change, build trust with frontline staff, and foster a culture of safety. A second safety component came directly from the pharmacy, recommending to prescribers that they adjust a dose or discontinue drugs that were duplicated. Finally, when providers had difficult, complex patient cases to manage, the PSO encouraged them to present these cases to our ad hoc Pain Committee for future recommendation on the treatment of these patients.

\section{Creating Position for Pain-Certified Nurse}

The aim of a Pain-Certified Nurse is to educate patients about tapering opioids and managing pain and stress. The main method is to simply be present with each patient for 45-60 min to allow patients an unrushed venue to discuss their situation, describe why they want to continue medications, discuss sources of pain and best treatments for pain, and begin to receive alternative treatments. The capacity to devote this time allows patients to gain a better understanding of why tapering is needed. It also boosts morale because other concerns are addressed and options are considered, encouraging a greater sense of control, which is known to reduce pain perception. To implement our new position of Pain-Certified Nurse, an RLNRC nurse case manager who has a background in palliative care was championed by the PSO and was endorsed by the ad hoc Pain Committee and by the Chief Nursing Officer to study for certification by the American Nurses Credentialing Center, while the Chief Executive Officer authorized funding for initial training. This nurse developed a job description for a full-time position, but during the study period this position was only part-time.

\section{Psychotherapy}

The emotional issues related to pain and its management are multifaceted and usually reflect a complex situation including loss of function, loss of identity, and loss of purpose. Therefore, we need to identify the contribution of psychic pain to maintaining and exacerbating the perception of physical pain. Accordingly, assessments by our interdisciplinary team included psychological issues and the constellation of factors that contribute to these issues. From these issues and factors, a treatment plan that outlined the progression of therapy in the short and long term was drawn up for individual and family therapy to assist the patient in developing a purposeful life and direction, which in turn helps to develop a sense of identity other than that of a patient or victim. The patient needs to have a reason to get up in the morning and to be around people. Whether as a volunteer, student, parent, etc., to 
be able to play a role in society aids in developing and maintaining his or her identity as a person.

\section{ADJUSTING OUR IMPLEMENTATION}

As a result of weekly case reviews by the ad hoc Pain Committee, two changes were made during the course of the study period. First, executive rounds conducted by the Chief Medical Officer and the PSO were shifted from being entirely staff oriented to directly visiting difficult patients, where we were able to carry out our communications campaign directly. Second, the Pain-Certified Nurse began seeing each patient more than once during inpatient stay. This adjustment was only partial because, during the study period, this nursing role was performed by a case manager as a parttime consultant in addition to her full-time position.

\section{MEASURING OUR PROGRESS}

To measure the outcomes of our intervention, we used data from the Pharmacy Department as well as data from the Interagency Services Department, a Los Angeles County institution that keeps electronic records for our hospital. Staff members of our Pharmacy Department on the ad hoc Pain Committee volunteered their time to create two specific measures of effectiveness: (1) the percentage of $\mathrm{SCl}$ inpatients who are on more than $30 \mathrm{mg} / \mathrm{d}$ of oral-morphine analgesic-equivalent dosage in one of our units where most patients are experiencing severe pain (the Jacqueline Perry Neuro-Trauma Institute [JPI], third floor) and (2) the percentage of all $\mathrm{SCl}$ inpatients taking more than 10 routine medications. Goal values were determined by the strategy set by our organization: 50 percent below baseline for oral-morphine equivalents on JPI third floor and 30 percent below baseline for polypharmacy.

Discovery methods were used to gain feedback on how well we were doing and to assess our direction for fine tuning. We created focus groups using already established, outpatient-run channels such as the Patient Advisory Counsel and support groups in RLANRC's Wellness Center. We brought different guests from around the hospital to provide new perspectives at our pain meetings. Their sharing of difficult cases allowed us to see what challenges they were facing (the flip side of the case-review intervention).

\section{OUTCOMES}

We reached our goals with a 56 percent decrease in the percentage of $\mathrm{SCl}$ inpatients on more than $30 \mathrm{mg} / \mathrm{d}$ of oral-morphine analgesic-equivalents on the JPI third floor (Figure (a)), and a 35 percent decrease in the percentage of polypharmacy ( $>10$ routine medications) for all RLANRC SCI inpatients (Figure (b)).

The largest shift in our opioid data occurred immediately following a blast email that the Chief Medical Officer sent out to hospital medical staff regarding the effort to lower overall morphine-equivalents hospital wide. Immediately, there was a drop in hospital-wide morphine equivalents (Figure (a)).

In the latter half of the study period, opioid use appeared to oscillate around the target level (Figure (a)). We believe this is due mainly to two factors. First, new patients arrive on opioids and then we taper them, but the length of stay is about 3 wk; so every time we decrease, we discharge and then new patients are admitted. Second, the Chief Medical Officer periodically sent emails, made calls, or conducted in-person rounds on the units to support the front-line clinicians who fear patient anger and dissatisfaction, emphasizing that we are doing this for the patients' health, not based on a moral judgment.

\section{LESSONS LEARNED}

Lesson 1: Unless a patient wants to change, progress will be difficult. Lesson 2: Different modalities of communication work for different people, so maximizing the number of avenues for communications was advantageous. Lesson 3: Having the support of executive-level administrators was crucial to our providers' efforts. It gave the team a feeling of safety and protection in trying progressive new approaches, and it increased the momentum and support for the efforts. Lesson 4: Sharing difficult cases gave hospital staff the opportunity to get involved in and take ownership over the new opioid policy's formation. Often, simply feeling heard, gaining awareness, and being able to speak about these challenges was enough for the staff to leave our meetings eager to champion our cause in their departments of the hospital. This mitigated the 


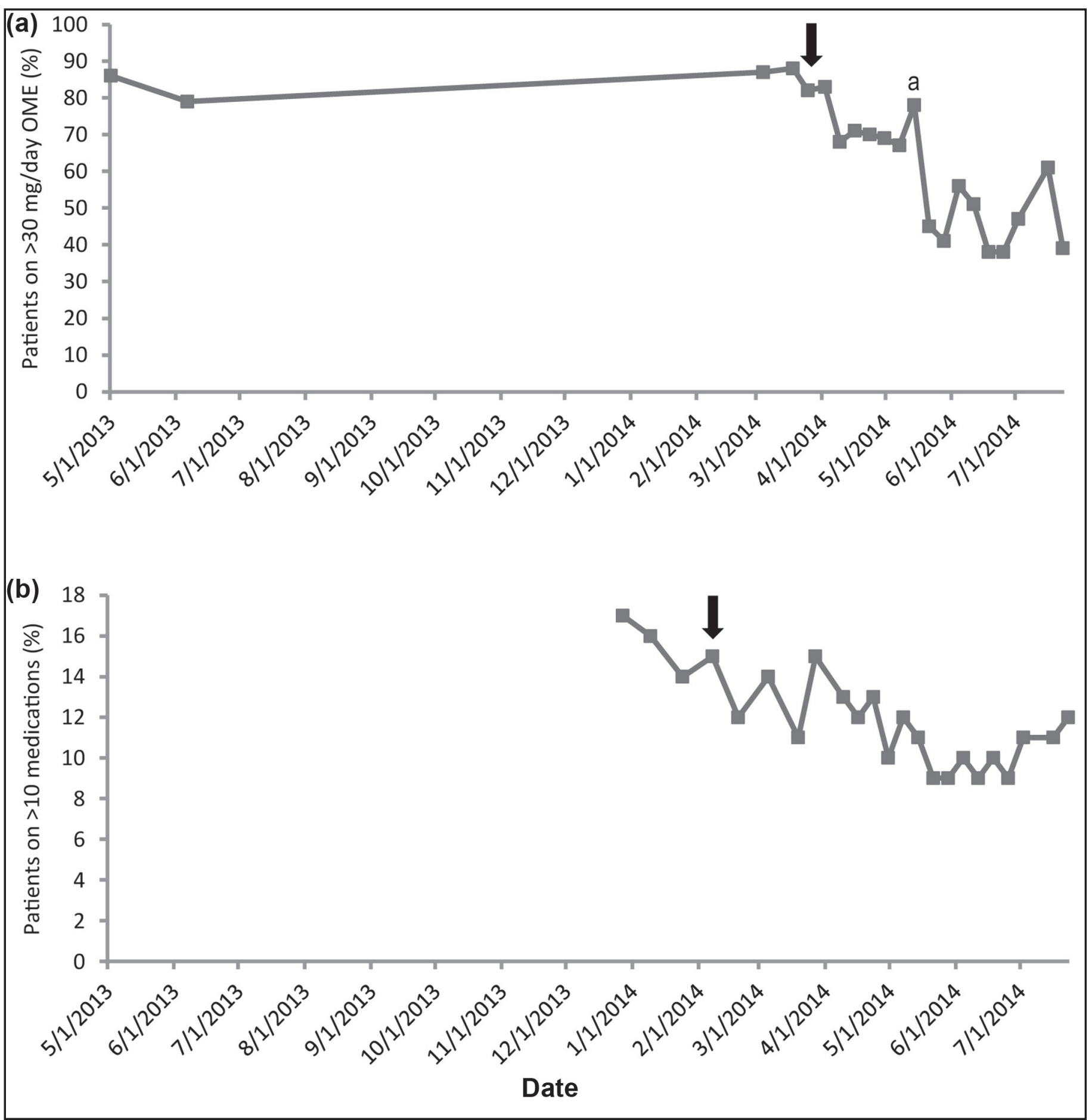

Figure.

Reduction in opioid prescriptions and polypharmacy for spinal cord injury (SCI) inpatients in response to interventions. (a) Time course shows percentage of $\mathrm{SCl}$ inpatients on $>30 \mathrm{mg} / \mathrm{d}$ of oral-morphine analgesic-equivalents (OMEs) before and during multiple coordinated interventions at Rancho Los Amigos National Rehabilitation Center (RLANRC). Data are from one hospital unit where most patients are experiencing severe pain following SCl. Arrow = intervention begins with dissemination of conversion table for morphine equivalents. $\mathrm{a}=$ Chief Medical Officer sends blast email on opioid combinations. (b) Time course shows percentage of all RLANRC SCI inpatients on $>10$ routine medications before and during interventions. Arrow = intervention begins when Patient Safety Officer starts contacting clinicians. 
tendency for individual silos within our large hospital to have differing interpretations of the original message.

\section{FUTURE DIRECTIONS}

An intranet site for centralizing information about patient pain is an ongoing project of the ad hoc Pain Committee that will draw from our lessons learned about communication. This site is intended to be a resource for information useful to patients as well as information for providers and hospital administrators.

The Pain-Certified Nurse is now a full-time position, allowing a series of consultations with each inpatient and also allowing a formal program of visits every $2 \mathrm{wk}$ for outpatients. The Pain-Certified Nurse also recently developed a support group for those with higher than average opioid use.

The University of Southern California (USC) Lifestyle Redesign ${ }^{\circledR}$ [10] Pain Management Program has been adapted by a clinical specialist in RLANRC's Occupational Therapy Department to help transition our more challenging inpatients to RLANRC's outpatient clinics. This adapted program imbeds routines for rest, sleep, comfort, and meaningful activities into daily activities to gain a sense of control and thereby reduce pain. The principles of Lifestyle Redesign include emphasis on social support, application of health-related knowledge, use of resources, focus on daily life activities in multiple settings, attention to life circumstances that affect risk, and individualization. This means working with the patient's fear of taking risks. Alternating periods of activity and rest are practiced and corrected to become aware of choices and gain control over his or her environment. Manuals of policies and procedures for doing this for patients with disabilities are being developed, such as the manual developed for the joint USC/RLANRC Pressure Ulcer Prevention Program [11].

Informed by this lifestyle approach, guest speakers have been invited to the support groups held in our Wellness Center to educate patients and conduct focus groups to obtain feedback on the opioid tapering issues (some inpatients have attended these sessions). It is our observation that this lifestyle program makes a very big contribution and it is rather unique to RLANRC and USC. This approach may have contributed to our outcomes by already giving some of the inpatients a greater sense of control and hope for meeting challenges, and also through feedback from the focus groups. In addition, to give consultative feed- back on lifestyle to pain-clinic providers, the occupational therapy specialist created a "virtual team" via periodic group emails, which we have perceived to be invaluable. Problems encountered in implementing our adapted lifestyle program include learning how to educate providers about nonmedical alternatives for pain management. This may entail having occupational therapists in the outpatient clinics.

\section{CONCLUSIONS}

Our ad hoc Pain Committee has successfully implemented the first iteration of hospital-wide changes geared toward reducing the use of opioids at RLANRC. Our measured outcomes and anecdotal observations illustrate the effectiveness of opioid tapering in a rehabilitation hospital using educational methods alone, without coercion of prescribers or patients. We consider this approach to be inherent in the definition of informed consent [8]. However, it is important that each hospital or facility take stock of its own particular patient and institutional challenges relating to opioid analgesic overuse. We hope that the model we are instituting at RLANRC will encourage other institutions to be proactive in determining and meeting their own needs in tapering opioid use. We all must bear in mind that $\mathrm{SCl}$ patients are not terminally ill and have a long life ahead of them and we have to make that life as healthy, productive, and inclusive as possible.

\author{
Alan Marc Atkins; ${ }^{1}$ Fernando Gonzalez, PhD; ${ }^{2}$ \\ Brian Joyo, PharmD; ${ }^{3}$ Mindy Lipson Aisen, MD ${ }^{1,4 *}$ \\ Departments of ${ }^{1}$ Medicine, ${ }^{2}$ Psychology, and \\ ${ }^{3}$ Pharmacy, RLANRC, Downey, CA; ${ }^{4}$ Keck School of \\ Medicine, USC, Los Angeles, CA \\ *Email: maisen@dhs.lacounty.gov
}

\section{ACKNOWLEDGMENTS}

\section{Author Contributions:}

Study concept and design: M. L. Aisen, F. Gonzales. Acquisition of data: A. M. Atkins, B. Joyo.

Drafting of manuscript: A. M. Atkins, M. L. Aisen, F. Gonzales, B. Joyo.

Financial Disclosures: The authors have declared that no conflicting interests exist. Stephen X. Arthur 
provided professional writing and editing of the article with funding from Rancho Research Institute, Inc.

Additional Contributions: The authors would like to acknowledge Robert Boucher, Judith Salazar, Stefan Bughi, Julia Habiby, and Michal Atkins for assistance in organizing the study.

\section{REFERENCES}

1. Addressing prescription drug abuse in the United States: Current activities and future opportunities [Internet]. Washington (DC): U.S. Department of Health and Human Services; 2013 [cited 2014 Aug 1]. Available from: http://www.cdc.gov/HomeandRecreationalSafety/pdf/HHS_Prescription_Drug_Abuse_Report_09.2013.pdf

2. Ballantyne JC, Shin NS. Efficacy of opioids for chronic pain: A review of the evidence. Clin J Pain. 2008; 24(6):469-78. [PMID:18574357] http://dx.doi.org/10.1097/AJP.0b013e31816b2f26

3. Mehendale AW, Goldman MP, Mehendale RP. Opioid overuse pain syndrome (OOPS): The story of opioids, Prometheus unbound. J Opioid Manag. 2013;9(6):42138. [PMID:24481931] http://dx.doi.org/10.5055/jom.2013.0185

4. Eriksen J, Sjøgren P, Bruera E, Ekholm O, Rasmussen NK. Critical issues on opioids in chronic non-cancer pain: An epidemiological study. Pain. 2006;125(12):172-79. [PMID:16842922] http://dx.doi.org/10.1016/j.pain.2006.06.009

5. Noble M, Treadwell JR, Tregear SJ, Coates VH, Wiffen PJ, Akafomo C, Schoelles KM. Long-term opioid management for chronic noncancer pain. Cochrane Database Syst Rev. 2010;(1):CD006605. [PMID:20091598]

6. Ullrich PM, Jensen MP, Loeser JD, Cardenas DD, Weaver FM. Pain among veterans with spinal cord injury. J Rehabil Res Dev. 2008;45(6):793-800. [PMID:19009466] http://dx.doi.org/10.1682/JRRD.2008.01.0005

7. Chou R, Fanciullo GJ, Fine PG, Adler JA, Ballantyne JC, Davies P, Donovan MI, Fishbain DA, Foley KM, Fudin J, Gilson AM, Kelter A, Mauskop A, O'Connor PG, Passik
SD, Pasternak GW, Portenoy RK, Rich BA, Roberts RG, Todd KH, Miaskowski C; American Pain Society-American Academy of Pain Medicine Opioids Guidelines Panel. Clinical guidelines for the use of chronic opioid therapy in chronic noncancer pain. J Pain. 2009;10(2): 113-130.e22. [PMID:19187889]

http://dx.doi.org/10.1016/j.jpain.2008.10.008

8. Prescribing opioids: Care amid controversy. Recommendations from the California Medical Association's Council on Scientific Affairs 2014 [Internet]. Sacramento (CA): California Medical Association; 2014 [cited 2014 Aug 1]. Available from: http://www.cmanet.org/ resource-library/detail/?item=prescribing-opioidscare-amid-controversy

9. Hyatt J, Steinberg S. Ensuring safe and appropriate prescription opioid use in Kaiser Permanente patients and the community [Internet]. Oakland (CA): California HealthCare Foundation; 2013 [cited 2014 Aug 1]. Available from: http://www.chcf.org/ //media/MEDIA\%20 LIBRARY\%20Files/PDF/C/PDF\%20CINwebinar102320130pioidUse.pdf

10. Mandel DR, Jackson JM, Zemke R, Nelson L, Clark FA. Lifestyle Redesign: Implementing the Well Elderly Program. Bethesda (MD): American Occupational Therapy Association, Inc; 1999.

11. Blanche El, Fogelberg D, Diaz J, Carlson M, Clark F. Manualization of occupational therapy interventions: Illustrations from the Pressure Ulcer Prevention Research Program. Am J Occup Ther. 2011;65(6):711-19. [PMID:22214116]

http://dx.doi.org/10.5014/ajot.2011.001172

This article and any supplemental material should be cited as follows:

Atkins AM, Gonzalez F, Joyo B, Aisen ML. Tapering opioid prescriptions and reducing polypharmacy for inpatients with spinal cord injury at Rancho Los Amigos National Rehabilitation Center. J Rehabil Res Dev. 2014;51(9):vii-xiv.

http://dx.doi.org/10.1682/JRRD.2014.08.0194

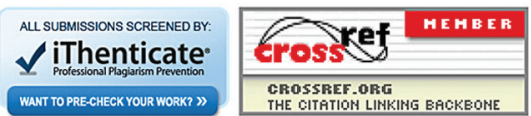


